\title{
Kimuras disease: a rare case of paediatric parotid swelling masquerading as pleomorphic adenoma without peripheral eosinophilia
}

\begin{abstract}
Kimuras disease is a chronic inflammatory disorder mostly affecting subcutaneous tissue, lymph nodes and salivary glands which has affinity for the Asian population. Histopathologically characterised by a lymphofolliculoid granuloma with infiltration of surrounding tissues by eosinophils, often with concomitant peripheral blood eosinophilia and elevated serum immunoglobulin E. TH2 cells are suspected to play an important role with increased levels of IL-5 and IgE.

We hereby present a case of left parotid swelling in paediatric age group which was gradually increasing in size. Radiological investigations showed heterogenous parenchyma with multiple hypoechoeic lesions in parotid. Peripheral blood picture gave normal eosinophil count. Superficial parotidectomy was carried out and final histopathology suggestive of Kimuras disease was made.
\end{abstract}

Keywords: kimuras, parotid, eosinophil
Volume 10 Issue 2 - 2018

\section{Aniketh Pandurangi, Madhuri Mehta, Pooja Sancheti}

Jindal Institute of Medical Sciences, India

Correspondence: Aniketh Pandurangi, Jindal Institute of Medical Sciences, Model Town Hisar Haryana, India, Tel 00919167640766, Email pandurangianiketh@gmail.com

Received: February 01, 20I8| Published: March 22, 2018

\section{Introduction}

Kimuras disease is a chronic inflammatory disorder believed to be an immune mediated disease having more affinity for asian population and $\mathrm{TH} 2$ cells are suspected to play an important role with increased levels of IL-5 and IgE.

Microscopically, there are lymphoid nodules with marked infiltration of eosinophils, formation of eosinophil micro abscesses.

\section{Case report}

Patient aged 12 years, male, presented to our tertiary care centre ENT outpatient department, with swelling below the left ear lobule since 2 years, insidious in onset, gradually increasing in size.

On examination, the swelling was around $4 \mathrm{cmx} 2 \mathrm{~cm}$, in the left parotid gland area, pruriginous, soft in consistency, nonpulsatile, nontender on palpation. Ear canal and tympanic membrane was normal. Facial nerve examination was normal. Nose and throat examination were normal.

Neck revealed a $1 \mathrm{~cm} \times 1 \mathrm{~cm}$, level II, left side lymphadenopathy, soft, nontender on palpation. There was no axillary or inguinal lymphadenopathy. Abdominal examination was normal.

Swelling was not associated with previous history of tuberculosis, dryness of mouth, skin lesions, joint pain or weight loss.

Ultrasonography showed heterogenous parenchyma with multiple hypoechoeic lesions in the left parotid. Computed tomography complemented the findings of sonography. Fine needle aspiration of parotid showed polymorphic population of lymphoid cells and plasma cells. Peripheral blood gave a picture of normal eosinophil count $(2 \%)$. With a provisional diagnosis of pleomorphic adenoma, superficial parotidectomy was carried out. Post operative recovery was good with no complications.

Final histopathology of specimen showed marked lympho-nuclear infiltrate forming lymphoid aggregates with multiple germinal centres and large number of eosinophils in aggregates, suggestive of Kimuras disease.

Patient has been following up since six months with no evidence of recurrence or complications (Figure 1-3).

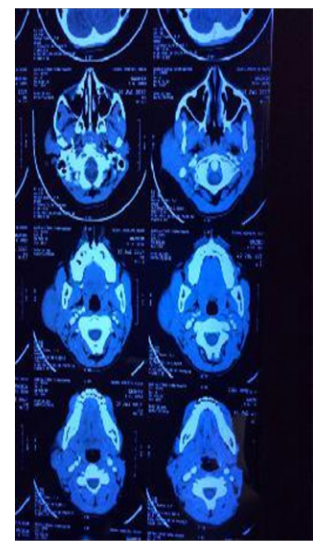

Figure I CT scan of Face axial cut showing left parotid swelling.

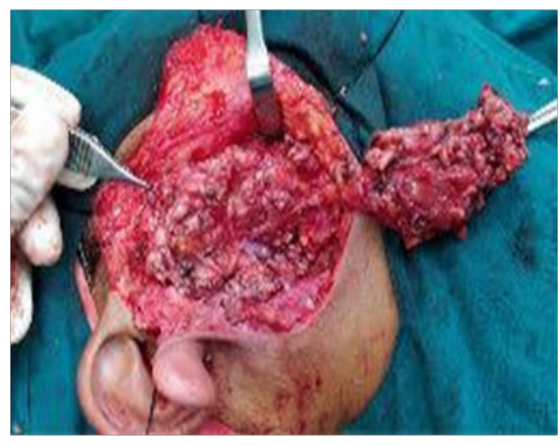

Figure 2 Intraoperative picture of superficial parotidectomy. 


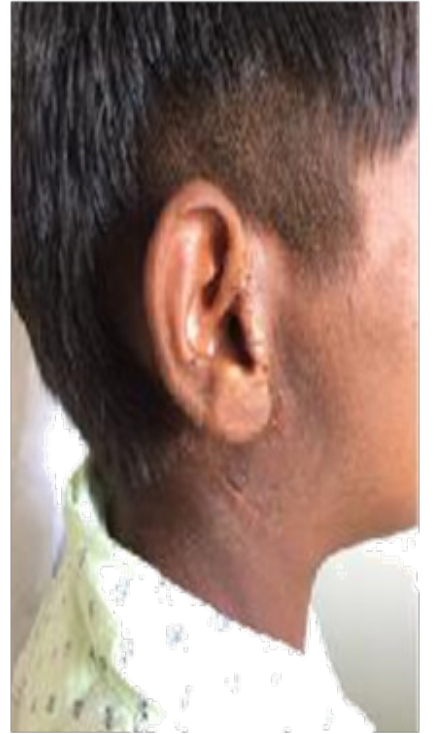

Figure 3 Post operative day 10.

\section{Discussion}

Kimuras disease is a rare disorder, usually affecting Asian population in third decade. ${ }^{1}$ Japan, China, Philippines, Vietnam and Indian subcontinent are the common countries from where this has been reported. ${ }^{2}$ Male sex tends to be affected more than female.

Microscopically, lesions exhibit eosinophilic lymphoid granulomas with vascular proliferation and variable degree of fibrosis. Immunochemistry reveals presence of $\mathrm{IgE}$ reticular network in germinal centres and IgE coated non-degranulated mast cells. ${ }^{3}$

Further leading points for diagnosis of Kimuras disease are blood eosinophilia and elevated serum IgE levels. Size of the lesion is said to have direct correlation with degree of blood eosinophilia (Figure 4). ${ }^{4}$

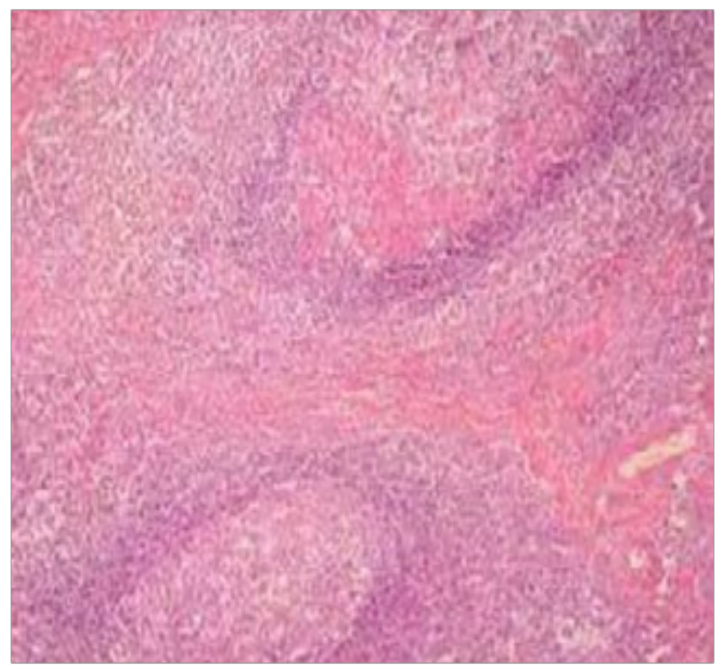

Figure 4 Follicular hyperplasia of lymph node with one follicle (upper) showing eosinophilic microabscess ( $\mathrm{H}$ and $\mathrm{E}$ stain, 100x).

The lesion that bears the closest resemblance to Kimuras is angiolymphoid hyperplasia with eosinophilia (ALHE). Both have predilection for head and neck region, clinical presentation as subcutaneous mass, presence of lymphoid infiltration with eosinophils and vascular proliferation. ${ }^{5}$ Rosai et all. ${ }^{6}$ later proved that both were different entities. Currently Kimuras is believed to be chronic allergic inflammatory process of un-known origin whereas ALHE is benign proliferate each disorder (Figure 5). ${ }^{7}$

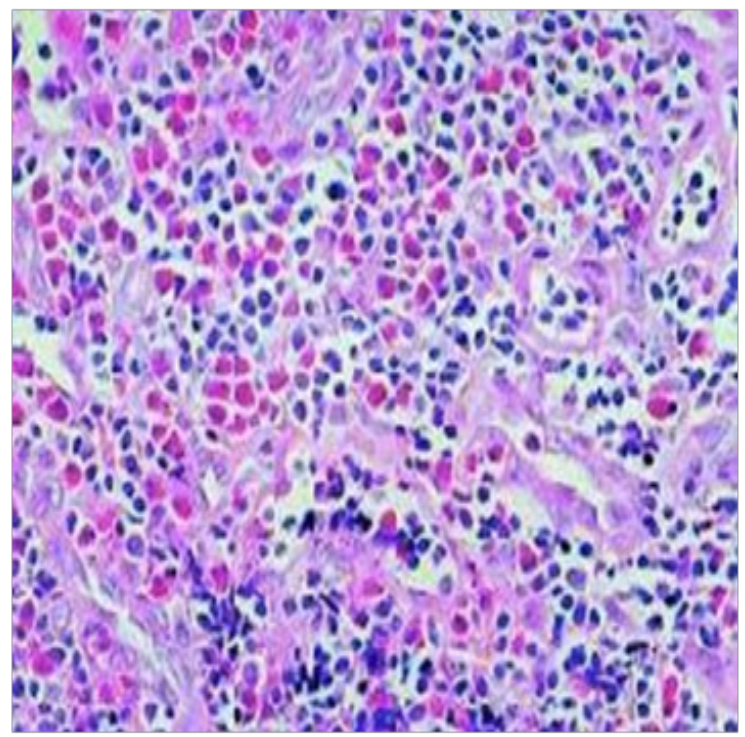

Figure 5 Numerous eosinophils seen along with Warthin - Finkeldey polykaryocytes ( $\mathrm{H}$ and $\mathrm{E}$ stain, 400x).

Kimuras disease of parotid is often misdiagnosed with more common lesions of parotid such as neoplastic lesions, Mikuliczs disease, angioimmunoblastic lymphadenopathy, which have been ruled out in histopathological study of excised specimen.

In asymptomatic cases, conservative management is adequate. Surgical excision is considered the first line of treatment in symptomatic patients but recurrence is frequent. ${ }^{8,9}$ Patients have to be counselled regarding recurrence. Topical and systemic steroids have also been effective. Other medical treatment like cetrizine, steroids, cyclosporins, retinoids have shown variable degree of success. Radiotherapy has also been used with local control rate of around $74 \%{ }^{10}$

\section{Conclusion}

Kimuras disease is a chronic inflammatory disorder of unknown origin. It involves subcutaneous tissues, salivary glands, lymph nodes in the head neck region with marked peripheral eosinophilia. We have presented this case of Kimuras disease with normal eosinophil count in blood. Although rare, this entity should be kept in mind while evaluating parotid swellings owing to its reported responsiveness to non surgical management and high rate of recurrence.

\section{Acknowledgment}

None.

\section{Conflict of interest}

None. 


\section{References}

1. Chen H, Thompson LD, Aguilera NS, et al. Kimura disease: A clinicopathologic study of 21 cases. Am J Surg Pathol 2004;28(4):505513.

2. Sud K, Saha T, Das A, et al. Kimura's disease and minimal change nephrotic syndrome. Nephrol Dial Transplant. 1996;11(7):1349-1351.

3. Hui PK, Chan JK, Ng CS, et al. Lymphadenopathy of Kimura's disease. Am J Surg Pathol. 1989;13(3):177-186.

4. Dik VK, van der Wiel BA, Vasmel WL. Kimura's disease of the parotid glands and multiple cervical lymph nodes. Neth J Med. 2010;68(4):175177.

5. Seregard S. Angiolymphoid hyperplasia with eosinophilia should not be confused with Kimura's disease. Acta Ophthalmol Scand. 2001;79(1):9193.
6. Rosai J, Gold J, Landy R. The histiocytoid hemangiomas. A unifying concept embracing several previously described entities of skin, soft tissue, large vessels, bone, and heart. Hum Pathol. 1979;10(6):707-730.

7. Chong WS, Thomas A, Goh CL. Kimura's disease and angioly mphoid hyperplasia with eosinophilia: Two disease entities in the same patient: Case report and review of the literature. Int J Dermatol. 2006;45(2):139145 .

8. Meningaud JP, Pitak-Arnnop P, Fouret P, et al. Kimura's disease of the parotid region: Report of 2 cases and review of the literature. J Oral Maxillofac Surg. 2007;65(1):134-140.

9. Bonfils P, Moya-Plana A, Badoual C, et al. Intraparotid Kimura disease. European Annals of Otorhinolaryngology, Head and Neck Diseases. 2013;130(2):87-89.

10. Hareyama M, Oouchi A, Nagakura H, et al. Radiotherapy for Kimura's disease: The optimum dosage. Int J Radiat Oncol Biol Phys 1998;40(3):647-651. 